\title{
ORIGINAL ARTICLE \\ Are the characteristics of the patient with a spinal cord injury changing?
}

\author{
V Sebastià-Alcácer ${ }^{1}, \mathrm{M}_{\text {Alcanyis-Alberola }}^{2}, \mathrm{M} \mathrm{Giner-Pascual}^{1}$ and $\mathrm{F}$ Gomez-Pajares $^{3}$
}

Study design: A retrospective analytical study.

Objective: To determine the epidemiologic pattern of spinal cord injury ( $\mathrm{SCl}$ ) over the last decade.

Setting: Patients admitted in the spinal cord injury unit at a university hospital between 1 January 2001 and 31 December 2013. Methods: A review of the clinical history of the patients was conducted. Patients were allocated according to traumatic (traffic and non-traffic accidents) or non-traumatic origin (tumour and non-tumour disease). Information about gender, age, admission and discharge date and cause, level and grade of spinal cord injury was collected. An analysis using the time-trend series was performed. Results: The average length of stay decreases 1.5 days quarterly, and the average patient's age increases 0.25 year quarterly. No trend was observed with respect to the number of cases.

Conclusion: Although the number of patients with an $\mathrm{SCl}$ caused by an accident has decreased and the average age of patients with an $\mathrm{SCl}$ has increased, it cannot be said that there has been a paradigm shift in patients with $\mathrm{SCl}$.

Spinal Cord (2014) 52, 29-33; doi:10.1038/sc.2013.128; published online 5 November 2013

Keywords: spinal cord injury; epidemiology; traffic accident; traumatic injuries; accident prevention

\section{INTRODUCTION}

Spinal cord injuries (SCIs) and the disabilities they cause are a great concern to clinicians, patients, relatives and the society in general. ${ }^{1}$

Studies from different countries report SCI incidences that vary from $8.3^{2,3}$ to $10.4^{4}$ up to $83^{5}$ cases per million. These reported results are influenced by many variables, such as inclusion of SCI patients who die before reaching the hospital and differences in the geographic and socio-political conditions of the country involved. According to Wyndaele, ${ }^{5}$ who reviewed the period until 2006, the incidence in the past 30 years has not substantially changed. In the study by Wyndaele, ${ }^{5}$ different publications from the United States and some from European, Asian and other countries were examined, but no studies from South America or Africa could be found.

Trauma is the most commonly reported cause of an SCI, having two peaks of incidence: one in people between 15 and 29 years of age (related to traffic accidents) ${ }^{6}$ and another in people above 65 years of age (related to accidental falls). ${ }^{7}$ According to these studies, different countries have implemented policies designed to prevent road accidents. $^{8}$ These traumatisms are more frequent in male individuals, with figures that vary depending on the consulted source. ${ }^{3,8,9}$ Falls from a height and working accidents are also among the most common causes of traumatic SCI. Non-traumatic causes, in turn, comprise vertebral spondylosis, tumour compression, vascular ischemia and congenital and inflammatory spinal cord diseases. ${ }^{10}$ In these cases, the incidence rate increases with age, and there are either no significant gender differences ${ }^{11}$ or slightly higher rates in male individuals. ${ }^{12}$
Recent studies show that there are significant variations in the epidemiology of SCI related to an increased incidence in elderly people due to falls and non-traumatic disorders. ${ }^{1}$

We found numerous epidemiological studies dated up to 2006 but few since then. The data are seen to have remained constant in Spain in recent decades. ${ }^{13}$

We noticed a number of trends in our unit. For example, we recorded a decrease in admissions attributable to traffic accidents. Traffic accidents in Spain have declined by a staggering $54 \%$ between 2003 and $2010 .{ }^{14}$ We also noticed an increase in the average age of patients. We believe that, to some extent, these variations can be imputable to the improved safety measures implemented in vehicles by the car industry, such as the innovations related to stability, sequential braking systems, airbags or seatbelts and other safety devices. In Spain, the road network has improved, with the construction, in recent years, of highways that connect the main cities. In addition, since 2006, new regulations have come up that enforce a lower speed limit and an increased amount to be paid as fine. We believe that the increase in the average age of SCI patients is attributable, among other reasons, to an increased life expectancy, improvements in healthcare, early detection of tumours and surgical treatments in elderly patients.

The above observations led us to conduct a review of patients' clinical records, with the objective to determine epidemiologic pattern of an SCI over the last decade.

\section{MATERIALS AND METHODS}

A retrospective analytical study was carried out, involving a review of the clinical records of patients admitted to the spinal cord injury unit of a tertiary hospital.

\footnotetext{
${ }^{1}$ Hospital Universitari I Politècnic La Fe from Valencia. Spinal Cord Injury Unit, Valencia, Spain; ${ }^{2}$ Hospital de Sant Francesc de Borja de Gandia. Servicio de Rehabilitación, Valencia, Spain and ${ }^{3}$ Hospital Sant Francesc de Borja de Gandia, Servicio de Medicina Preventiva, Valencia, Spain

Correspondence: V Sebastià-Alcácer, Servicio de Rehabilitacián, Hospital Universitari I Politècnic La Fe from Valencia. Spinal Cord Injury Unit, Bulevar Sur s/n, Valencia 46026, Spain.

E-mail: vicen1@msn.com

Received 8 December 2012; revised 20 September 2013; accepted 24 September 2013; published online 5 November 2013
} 
Study period

Data were collected from the patients admitted to the unit from 1 January 2001 to 31 December 2010.

\section{Subjects}

The following inclusion criteria were established:

(1) patients with SCI diagnosed by physicians with ample experience and whose level and grade of injury according to the AIS classification ${ }^{15}$ was assessed;

(2) request permission from the Medical Records committee of our hospital to access clinical information;

(3) all patients who were subjected to MRI evaluation, which revealed an SCI.

Patients were classified as SCI of traumatic origin or SCI of non-traumatic origin according to the aetiology of the lesions. Within the first group, patients were further divided into traffic or non-traffic accident (accidental falls, falls from a height, accidents while driving, aggressions or other causes). Within the second group, patients were divided into tumour or non-tumour disease (inflammatory, vascular, degenerative or infectious disease or other diseases).

Our exclusion criteria were as follows: patients with cauda equina; patients with spinal concussion defined as transient interruption marrow function after trauma, no radiographic evidence of bone disease or spinal cord and a full recovery in a short space of time; and patients with functional disorders, with no objectified organic cause, linked to conversion disorder or simulators.

\section{Settings}

The Spinal Cord Injury Unit in which the study was carried out is the reference unit for a recruitment population of 5.1 million. ${ }^{16}$ This reference unit receives patients from both its own hospital and other centres in the region and admits patients for acute and chronic treatment. We, therefore, consider that all SCI patients in the region have been evaluated in our unit, with the exception of patients with an SCI secondary to the end-stage malignant disease and patients with an SCI due to working accidents, as the latter were transferred to another hospital.

\section{Variables}

For each patient, we collected the following information: gender, age, length of stay, cause of SCI and level and grade of the lesion following the AIS classification. ${ }^{15}$

\section{Statistical methods}

A descriptive analysis of the patients included was performed. We calculated the cumulative incidence per million population of overall SCI per year with reference to the population of Comunitat Valenciana. For all other variables, we used the mean and standard deviation to describe the quantitative variables and the absolute number and percentage for categorical variables. A bivariate analysis was then performed according to the origin of an SCI (traumatic or non-traumatic). For quantitative variables, the Student's $t$-test was used and for categorical variables, the Chi-square test was used. For the average stay, the cumulative survival was calculated using the Kaplan-Meyer estimator, and the curves were compared using the log-rank test. To describe temporal variations in the number of cases, a time-trend series analysis was performed by fitting a Poisson regression model. For the series of age and length of stay, a linear regression model was adjusted for explanation. The time unit was defined quarterly and was used to estimate the linear trend of the series and seasonality. We worked with a confidence interval of 95\%. To perform statistical analysis, we used the SPSS v.18 program (SPSS Inc., Chicago, IL, USA) y STATA SE v.11 (StataCorp, College Station, TX, USA).

\section{RESULTS}

The spinal cord injury unit admitted 509 patients during the study period. As access to clinical records for data collection was not possible in four cases, therefore, these patients were excluded. Patients who suffered from cauda equina, spinal contusion and functional

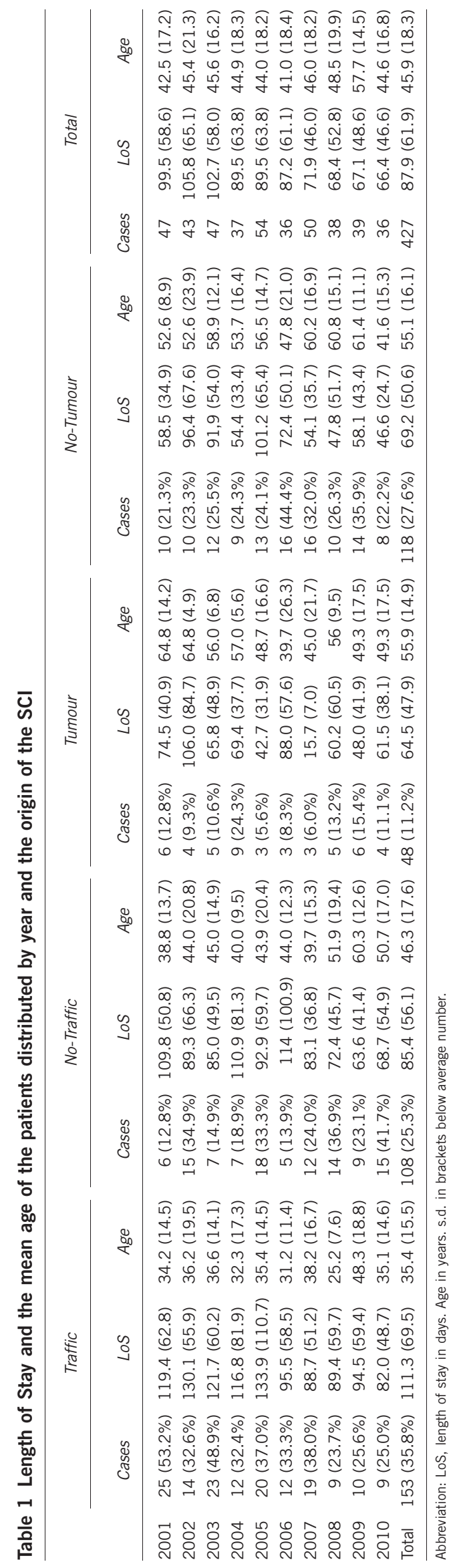




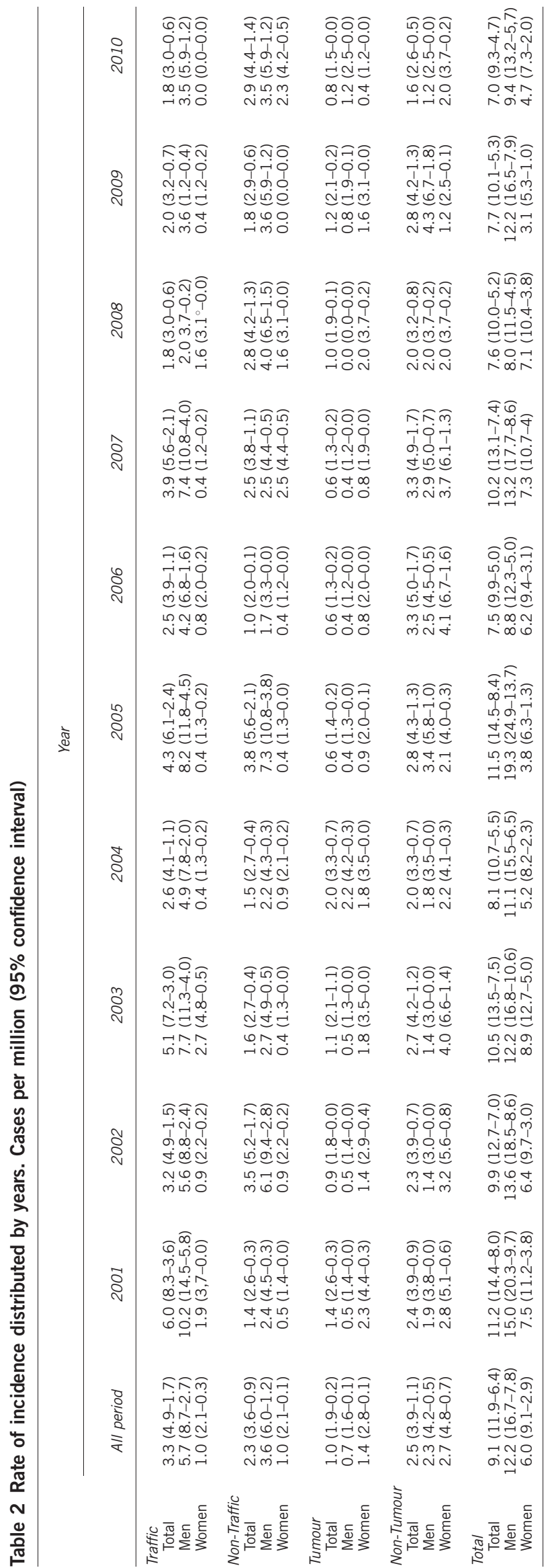

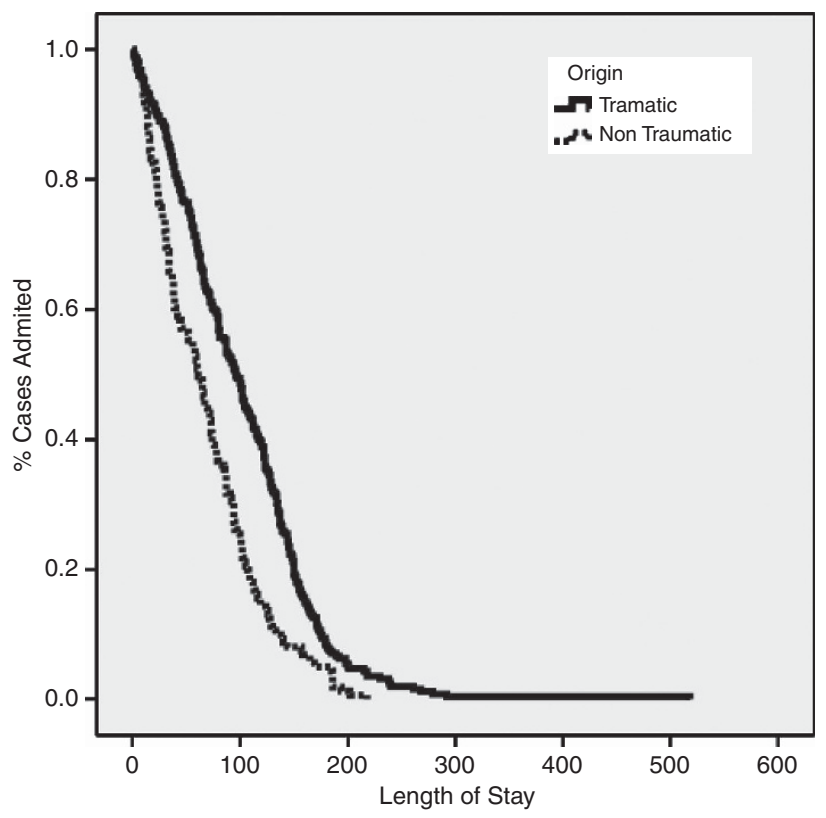

Figure 1 Survival analysis.

disorders were also excluded. A total of 427 patients met the inclusion criteria, with a mean age of 45.9 years (standard deviation (s.d.) 18.3).

Table 1 shows the average stay and the average age of patients distributed on the basis of the sources and years of injury. Patients who suffered a traffic accident were younger $(P<0.001)$ than the patients in other groups. Patients diagnosed with tumour were older $(P<0.001)$. Grade A and B patients were younger than those with $\mathrm{C}$ and $\mathrm{D}$ grades $(P<0.001)$. No influences by gender were found.

Table 2 shows the SCI incidence during the study period. Between 2001 and 2010, the SCI incidence due to traffic accidents had decreased by $59.4 \%(P=0.07)$; a test of trend was performed.

Figure 1 shows the survival curve under traumatic or nontraumatic patients. Patients with traumatic injury were hospitalized for longer. Both curves are different (log-rank 0.001).

In the time series analysis, we observe that the average stay decreases by 1.5 days quarterly $(P<0.05)$ (see Figure 2 ). Patients admitted during the 1st and 3rd quarter were hospitalized for an average of 20 days longer than patients admitted during the 2nd and 4th quarter. The length of stay for patients with complete injury (grades A and B) was greater than that for the patients with incomplete injury (grades $\mathrm{C}$ and $\mathrm{D})$. The mean patient age increases by 0.20 years quarterly $(P<0.05)$. With respect to the number of cases, there was no longterm trend $(P=0.216)$. With respect to gender distribution, we did not find any trend in the proportion of women (Table 3 ).

\section{DISCUSSION}

Spinal cord injuries have a major impact on the patient's quality of life. Multidisciplinary teams strive to restore the patient's maximum possible functional level and independence. ${ }^{1}$

The data published until 2005 clearly reflect the model of patients with an SCI. ${ }^{13,17}$ The epidemiological trend seems to have stabilized in recent decades. ${ }^{5}$ The most consolidated profile appeared to correspond to that of a man aged between 35 and 45 years, with an SCI caused by a traffic accident and involving complete spinal cord lesions. $5,13,18$

According to the latest evidence available, SCIs due to traffic accidents account for the $43 \%$ of the registered cases. ${ }^{13}$ Those most commonly affected are men between 35 and 45 years who ride motor 


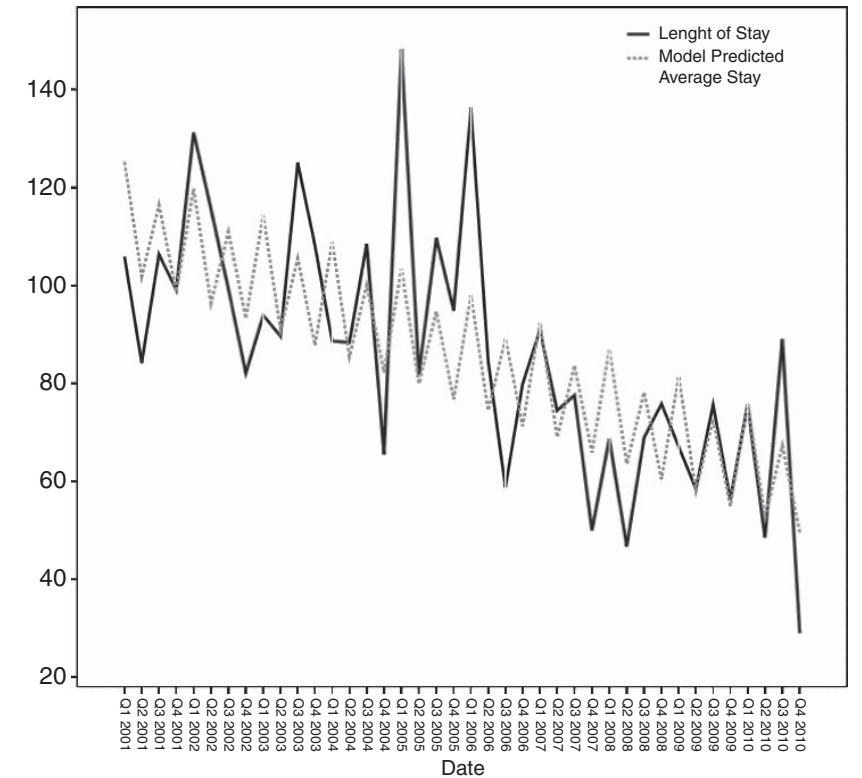

Figure 2 Evolution of the length of stay compared with the model predicted.

vehicles. This serves to directly define the predominant epidemiological characteristics in the last decades. In our study, the percentage of SCI cases attributable to traffic accidents between 2001 and 2005 was found to be $41 \%$, which is consistent with the data from the rest of the country.

One of the reasons, we believe, why traffic accidents provoke such a high incidence of SCIs is speed, as speeding is known to be a key element in accidents with severe consequences. ${ }^{19}$ In order to palliate this situation, the automobile industry has developed different safety measures such as the seatbelts, which reduce mortality risk and serious injury in case of collision. ${ }^{20}$ Some security measures are complementary, such as the use of airbags along with seatbelts; it is known that the use of airbags without concomitant use of the seatbelt has been related to cervical injuries. ${ }^{21}$ Seatbelt use has also been related to an increased incidence of cervical lesions. ${ }^{22}$

Circumstances such as these have led to a great decrease in traffic events, ${ }^{23}$ resulting in fewer patients with SCIs due to traffic accidents and a variation in the epidemiological data collected to date.

We found a progressive decline in the incidence of SCI caused by traffic accidents. We know of no other studies available offering such updated information for comparative purposes.

One finding that surprised us is that we have not found changes with respect to the sex ratio. The male/female ratio of $2: 1$ is stable (3.9/1 $13-2.6 / 1^{18}$ according to the literature).

In our study, we recorded a significant reduction in the mean length of stay; there has been a reduction of 6 days per year. We attribute this decrease to the aforementioned descend in traffic accidents and the lesser severity of the patients' condition. Changes in the length of stay may be attributable to an improvement in the support network of regional hospitals. We allow patients to perform the last phase of rehabilitation treatments in such hospitals and therefore achieve an early discharge.

We consider that the reduction in the mean length of stay can be attributable to a lower patient acuity associated with the everincreasing safety measures. Technical advances have improved automobile safety with better braking systems and safer steering wheels
Table 3 Differences between sexes distributed by year and cause of injury. $n(\%)$

\begin{tabular}{|c|c|c|c|c|c|c|}
\hline \multirow[t]{2}{*}{ Sex } & \multirow[t]{2}{*}{ Year } & \multicolumn{4}{|c|}{ Origin } & \multirow[t]{2}{*}{ Total } \\
\hline & & Traffic & No-Traffic & Tumour & No-Tumour & \\
\hline \multirow[t]{11}{*}{ Women (cases) } & 2001 & $4(25.0)$ & $1(6.3)$ & $5(31.3)$ & $6(37.5)$ & 16 \\
\hline & 2002 & $2(14.3)$ & $2(14.3)$ & $3(21.4)$ & $7(50.0)$ & 14 \\
\hline & 2003 & $6(30.0)$ & $1(5.0)$ & $4(20.0)$ & $9(45.0)$ & 20 \\
\hline & 2004 & $1(8.3)$ & $2(16.7)$ & $4(33.3)$ & $5(41.7)$ & 12 \\
\hline & 2005 & $1(11.1)$ & $1(11.1)$ & $2(22.2)$ & $5(55.6)$ & 9 \\
\hline & 2006 & $2(13.3)$ & $1(6.7)$ & $2(13.3)$ & $10(66.7)$ & 15 \\
\hline & 2007 & $1(5.6)$ & $6(33.3)$ & $2(11.1)$ & $9(50.0)$ & 18 \\
\hline & 2008 & $4(22.2)$ & $4(22.2)$ & $5(27.8)$ & $5(27.8)$ & 18 \\
\hline & 2009 & $1(12.5)$ & $0(0.0)$ & $4(50.0)$ & $3(37.5)$ & 8 \\
\hline & 2010 & $0(0.0)$ & $6(50.0)$ & $1(8.3)$ & $5(41.7)$ & 12 \\
\hline & Total & $22(15.5)$ & 24 (16.9) & $32(22.5)$ & $64(45.1)$ & 142 \\
\hline \multirow[t]{11}{*}{ Men (cases) } & 2001 & $21(67.7)$ & $5(16.1)$ & $1(3.2)$ & $4(12.9)$ & 31 \\
\hline & 2002 & $12(41.4)$ & $13(44.8)$ & $1(3.4)$ & $3(10.3)$ & 29 \\
\hline & 2003 & $17(63.0)$ & $6(22.2)$ & $1(3.7)$ & $3(11.1)$ & 27 \\
\hline & 2004 & $11(44.0)$ & $5(20.0)$ & $5(20.0)$ & $4(16.0)$ & 25 \\
\hline & 2005 & $19(42.2)$ & $17(27.8)$ & $1(2.2)$ & $8(17.8)$ & 45 \\
\hline & 2006 & $10(47.6)$ & $4(19.0)$ & $1(4.8)$ & $6(28.6)$ & 21 \\
\hline & 2007 & $18(56.3)$ & $6(18.8)$ & $1(3.1)$ & 7 (21.9) & 32 \\
\hline & 2008 & $5(25.0)$ & $10(50.0)$ & $0(0.0)$ & $5(25.0)$ & 20 \\
\hline & 2009 & $9(29.0)$ & $9(29.0)$ & $2(6.5)$ & $11(35.5)$ & 31 \\
\hline & 2010 & $9(37.5)$ & $9(37.5)$ & $3(12.5)$ & $3(12.5)$ & 24 \\
\hline & Total & $131(46.0)$ & $84(29.4)$ & $16(5.6)$ & $54(18.9)$ & 285 \\
\hline
\end{tabular}

and interiors. This situation, along with improvements in road conditions and a stricter legislation, appears to be the reason behind the important decrease in traumatic SCIs due to traffic accidents. In the same way, we attribute the decrease in grade A injuries to an improved facility for patient transfer to hospitals, better fracture-zone immobilization and an improved patient oxygenation facility to avoid spinal cord damage.

Another observation worth noting is the mean patient age, initially established as 35 to 45 years. ${ }^{18}$ The literature also refers to a second incidence peak at around 65 years, attributable to falls and degenerative disease. In the analysis, we can see that there is an increase in the average age by 1 year per year. The tendency is characterized by an increase in mean patient age, probably as a result of fewer admissions of young individuals due to traffic accidents and an increased life expectancy of the number of elderly patients with vascular, tumour or degenerative disease.

Considering the results in the study, it can be concluded that the paradigm of the patient with spinal cord injury has not radically changed and continues to correspond to a young male patient with complete SCI, mainly caused by a traffic accident. A tendency towards fewer traffic accidents has been observed, which in the long term will lead to a change in the type of patient we are used to treat.

On the basis of these findings, new future perspectives arise. For example, our data could be compared with those of other national or international centres in order to establish whether there is a genuine tendency towards a change in the paradigm of patients with an SCI. Prospective studies could also be designed to explore in more detail traffic accidents, focused in identifying risk factors and adopting strategies to deal with them. 
The main limitation of our study is its retrospective design, depending upon clinical histories compiled by other colleagues. For a more detailed study of traffic accidents, we could have divided patients into different subgroups, such as pedestrian, driver, passenger and motorcycle rider, and tried to identify the highest risk category.

\section{CONCLUSIONS}

Although there has been a decline in the number of SCI patients of traumatic origin and an increase in the average age of SCI patients, we cannot confirm that there has been a paradigm shift in patients with an SCI.

The average SCI patient in our region remains to be a 44 -year-old patient, with an average length of stay of 66 days and a male/female ratio of 2:1 and an SCI lesion of traumatic origin.

\section{DATA ARCHIVING}

There were no data to deposit.

\section{CONFLICT OF INTEREST}

The authors declare no conflict of interest.

1 van den Berg ME, Castellote JM, Mahillo-Fernandez I, de Pedro-Cuesta J. Incidence of spinal cord injury worldwide: a systematic review. Neuroepidemiology 2010; 34: 184-192; discussion 192.

2 van Asbeck FW, Post MW, Pangalila RF. An epidemiological description of spinal cord injuries in The Netherlands in 1994. Spinal Cord 2000; 38: 420-424.

3 Cripps RA, Lee BB, Wing P, Weerts E, Mackay J, Brown D. A global map for traumatic spinal cord injury epidemiology: towards a living data repository for injury prevention. Spinal Cord 2011; 49: 493-501.

4 Warren S, Moore M, Johnson MS. Traumatic head and spinal cord injuries in Alaska (1991-1993). Alaska Med 1995; 37: 11-19.

5 Wyndaele M, Wyndaele JJ. Incidence, prevalence and epidemiology of spinal cord injury: what learns a worldwide literature survey? Spinal Cord 2006; 44: 523-529.

6 Albert T, Ravaud JFTetrafigap group. Rehabilitation of spinal cord injury in France: a nationwide multicentre study of incidence and regional disparities. Spinal Cord 2005; 43: 357-365.
7 Pickett W, Simpson K, Walker J, Brison RJ. Traumatic spinal cord injury in Ontario, Canada. J Trauma 2003; 55: 1070-1076.

8 O'Connor RJ, Murray PC. Review of spinal cord injuries in Ireland. Spinal Cord 2006; 44: 445-448.

9 Karacan I, Koyuncu H, Pekel O, Sumbuloglu G, Kirnap M, Dursun H et al. Traumatic spinal cord injuries in Turkey: a nation-wide epidemiological study. Spinal Cord 2000; 38: 697-701.

10 New PW, Rawicki HB, Bailey MJ. Nontraumatic spinal cord injury: demographic characteristics and complications. Arch Phys Med Rehabil 2002; 83: 996-1001.

11 McKinley WO, Seel RT, Hardman JT. Nontraumatic spinal cord injury: incidence, epidemiology, and functional outcome. Arch Phys Med Rehabil 1999; 80: 619-623.

12 New PW, Sundararajan V. Incidence of non-traumatic spinal cord injury in Victoria, Australia: a population-based study and literature review. Spinal Cord 2008; 46: 406-411.

13 Mazaira J, Labanda F, Romero J, Garcia M, Gambarruta C, Sanchez A et al. [Epidemiología de la lesión medular y otros aspectos]. Rehabilitación (Madr) 1998 ; 32: 365-372.

14 La principales cifras de siniestralidad vial 2010. 2010; Available at http://www.dgt. es/was6/portal/contenidos/es/seguridad_vial/estadistica/publicaciones/princip_cifras siniestral/cifras siniestralidadl011.pdf. Accessed 9/1, 2012.

15 American Spinal Injury Association. Reference Manual of the International Standards for Neurological Classification of Spinal Cord Injury. American Spinal Injury Association: Chicago, IL, USA, 2003

16 Real Decreto 1612/2010. 2010 7/12/2010 http://www.boe.es/boe/dias/2010/12/23/ pdfs/BOE-A-2010-19706.pdf. Accessed 23/4/2013.

17 Alcaraz Rousselet M, Mazaira Alvarez J. Epidemiología. In: Esclarin de Ruiz A editor. Lesión Medular Enfoque Multidisciplinario, 1st ed. Panamericana: Madrid, 2010, p 11-17.

18 Garcia-Reneses J, Herruzo-Cabrera J, Martinez Moreno M. Epidemiological study of spinal cord injuty in Spain. Paraplegia 1991; 28: 180-190.

19 Cameron MH, Elvik R. Nilsson's Power Model connecting speed and road trauma: applicability by road type and alternative models for urban roads. Accid Anal Prev 2010; 42: 1908-1915.

20 Beck LF, Shults RA. Seat belt use in States and territories with primary and secondary laws-United States, 2006. J Safety Res 2009; 40: 469-472.

21 Donaldson WF 3rd, Hanks SE, Nassr A, Vogt MT, Lee JY. Cervical spine injuries associated with the incorrect use of airbags in motor vehicle collisions. Spine 2008; 33: 631-634.

22 Reed MA, Naftel RP, Carter S, MacLennan PA, McGwin G Jr, Rue LW 3rd. Motor vehicle restraint system use and risk of spine injury. Traffic Inj Prev 2006; 7: 256-263.

23 Anuario estadístico de accidentes 2009. 2009; Available at http://www.dgt.es/was6/ portal/contenidos/es/seguridad_vial/estadistica/publicaciones/anuario_estadistico/ anuario estadistico013.pdf. Accessed 3/26, 2011 